\title{
DAMIANO CANALE(1D
}

\author{
THE OPACITY OF LAW: ON THE HIDDEN IMPACT \\ OF EXPERTS’ OPINION ON LEGAL DECISION-MAKING
}

(Accepted 10 March 2021)

\begin{abstract}
It is well known that experts' opinion and testimony take on a decisive weight in judicial fact-finding, raising issues and perplexities that have long been under scholarly scrutiny. In this paper I argue that expert's opinions have a much wider impact on legal decision-making. In particular, they may generate a problem that I will call 'the opacity of law'. A legal text, such as a statute or regulation, becomes opaque if a legal authority is not able to grasp its full linguistic content but is nevertheless in a position to use it, thanks to an expert' opinion, in legal decision-making. When this occurs, not only do experts contribute to factfinding but also to determining the content of the law. In the paper I analyse the linguistic and cognitive sources of this phenomenon, its characteristics and troublesome consequences, and the different kinds of opacity that may affect legal decision-making.
\end{abstract}

\section{INTRODUCTION}

Much of what we know depends on what others tell us. Thanks to news reports, for example, we know the latest developments in a global pandemic; thanks to historians' accounts we know on what day the Titanic sank; thanks to scientists' indications we come to know that molybdenum is a sulfur catalyst. The role, in some ways obvious, that the testimony of others carries out in the construction of our knowledge has aroused rich debate in epistemology. 
According to some, knowledge has an eminently social character, to the point that it can not be attributed to a single individual but to an entire community. ${ }^{1}$ It is so because our beliefs do often not depend on our experience but on what others tell us, and on the epistemic credibility that the people bestow on them. ${ }^{2}$ In the social construction of knowledge a crucial role is entrusted therefore to experts, on whom the transmission of knowledge depends. It so happens that the reasons that justify the beliefs of the experts often replace our own, although experts' reasons are for us, in most cases, inaccessible.

This applies not only to everyday experience but also to the law. Expert opinions in the fields of genetics, epidemiology, environment, food, information technology, finance, engineering, etc. currently take on a relevant weight in legal proceedings, raising issues and perplexities that have long been the object of scholarly attention. These issues involve the selection of experts, their objectivity and impartiality, the admissibility and probative value of expert testimony, as well as the reliability of the scientific models on which expert opinions are based. Furthermore, scientific knowledge may be uncertain and controversial. When this happens, judges are called upon to make choices with regard to the 'best science' that go beyond their professional skills. ${ }^{3}$

However, it is not the discussion of these problems that the pages that follow are dedicated. The point that I will try to make in this article is that the role given to experts in the law raises much wider issues - issues that have an impact not only on fact finding, but also on many other aspects of legal decision-making. More precisely, I will argue that experts' opinion and testimony may generate a peculiar problem that I will call 'opacity of law'. Within the meaning of this article, a legal text, such as a statute or a regulation, is opaque

\footnotetext{
${ }^{1}$ See, e.g., Alvin I. Goldman, Knowledge in a Social World (Oxford: Oxford University Press, 1999); Frederick Schmitt, "Testimonial Justification and Transindividual Reasons", in J. Lackey and E. Sosa (eds), The Epistemology of Testimony (Oxford: Oxford University Press, 2006), pp. 193-224; Adrian Haddock, Alan Millar and Duncan Pritchard (eds), Social Epistemology (Oxford: Oxford University Press, 2010); Miranda Fricker, Peter Graham, David Henderson, Nikolaj Jang Lee and Linding Pedersen (eds), The Routledge Handbook of Social Epistemology (New York: Routledge, 2019).

${ }^{2}$ Brian Loar, "Social Content and Psychological Content", in R.H. Grimm and D.D. Merrill (eds), Contents of Thought (Tucson: University of Arizona Press, 1988), p. 118.

${ }^{3}$ For a reasoned framework of the problems associated with experts' opinion and testimony see, e.g., Richard Eggleston, Evidence, Proof and Probability (London: Weidenfeld \& Nicolson, 1983), p. 124 ff.; Cecil A.J. Coady, Testimony. A Philosophical Study (Oxford: Clarendon Pres, 1992), chap. 16; Susan Haack, "An Epistemologist in the Bramble-Bush: At the Supreme Court with Mr. Joiner", Journal of Health Politics, Policy and Law 26 (2001): pp. 217-247.
} 
if a legal authority is not able to grasp its full linguistic content but is nevertheless in a position to use it, thanks to an expert's opinion, in legal decision-making. ${ }^{4}$ When this occurs, not only do experts contribute to fact-finding but also to determining the content of the law. To explain what I mean by opaque law, however, I will start with an example.

\section{WHEN THE LAW BECOMES OPAQUE}

Imagine that a judge is entrusted with the decision of a case concerning a chemical substance. Let us call this substance 'Psidax'. The judge is requested to decide whether the use of Psidax is permitted or prohibited according to the law. Furthermore, imagine that the statutory regulation of the subject contains expressions such as ' $\mathrm{XYZ}$ is prohibited' and 'ABC is permitted', where $X Y Z$ and $A B C$ are chemical symbols that the judge is not able to understand since she does not master the language of chemistry: in the judge's eyes chemical symbols are meaningless scribbles. To decide the case, the judge then appoints a panel of experts who are called upon to testify with regard to the chemical composition of Psidax. More precisely, the panel is asked to ascertain whether Psidax is $\mathrm{XYZ}, \mathrm{ABC}$, or something else. After careful consideration, the experts come to the following conclusion: 'Psidax is XYZ'. Thanks to the information provided by the experts, the judge can decide the case by means of a simple syllogism: 'Since XYZ is prohibited, and Psidax is XYZ, then Psidax is prohibited'.

Now, one could argue that the decision is undoubtedly correct. According to a popular canon of legal interpretation, when a case is clearly covered by the language of the law no further interpretive effort is required from the judge. ${ }^{5}$ If $X Y Z$ is prohibited, and the

\footnotetext{
${ }^{4}$ I assume that the full content of a linguistic expression is constituted by its semantic content plus the pragmatic enrichment of semantic content that takes place in the communicative context in which the expression is uttered. See, e.g., Jason Stanley, "Semantics in Context", in G. Preyer and G. Peter (eds), Contextualism in Philosophy Knowledge, Meaning, and Truth (Oxford: Oxford University Press, 2005), pp. 221-253; François Recanati, "Pragmatic Enrichment", in G. Russel and D. Graff Fara (eds), The Routledge Companion to Philosophy of Language (New York: Routledge, 2013), pp. 67-78.

5 The "literal rule" or "plain meaning rule" can be justified on the basis of different methodologies of legal interpretation - such as textualism, originalism, intentionalism - depending on the way in which the plain meaning of a legal text is identified. Cf., e.g., Frederick Schauer, "Statutory Construction and the Coordinating Function of Plain Meaning”, The Supreme Court Review (1990): pp. 231-256. Notice that the argument presented in this article is not directed against a specific interpretive methodology. As I will try to show, the opacity of law is a relevant problem independent of the interpretive methodology and the theory of legal content one subscribes to.
} 
Psidax is an instance of $\mathrm{XYZ}$, as stated by the experts, a different solution of the case would emerge from a judicial manipulation of the law. As Lord Diplock once argued, 'Where the meaning of the statutory words is plain and unambiguous it is not for the judges to invent fancied ambiguities as an excuse for failing to give effect to its plain meaning because they consider the consequences for doing so would be inexpedient, or even unjust or immoral. ${ }^{6}$

Even if we embrace this standpoint, however, it should be noted that the case was decided although the judge had a very limited knowledge of the linguistic content of the statute that she applied. We take for granted that the judge is able to master the grammar and syntax of the language used by the legislature, and that she also understands the non-referential components of the statutory text ('prohibited'; 'permitted'). However, she has no idea about XYZ, $\mathrm{ABC}$ and the characteristics of Psidax, that is to say about the subject of the regulation. The judge does not understand the content of the expression that carries out a referential function in the statute, on which the legal qualification of the facts depends. She has limited herself to copying some mysterious chemical symbols found in a statute into the legal decision based on the opinion provided by the experts, thus fixing the reference of these symbols as if they were proper names or rigid designators. ${ }^{7}$ In short, the judge decided the case as if she were a decision-making machine.

The moral of this example is as follows: the act of fixing the reference of linguistic expressions that we do not understand, making use of an experts' opinion, is neither sufficient to guarantee our understanding of the statute in which these expressions recur nor to allow us to interpret them. Indeed, we can not say that we have understood or interpreted a statute if the starting point of these activities (the legal text) and its point of arrival (its full content) are not intelligible to us. I will call this phenomenon 'opacity of law'. In the perspective that I will defend in this article, a legal text is opaque if a legal authority fixes its reference on the basis of an expert's

\footnotetext{
${ }^{6}$ Duport Steel v. Sirs, 1 All ER 529 (1980).

${ }^{7}$ According to Kripke, proper names are rigid designators, i.e., they refer to the same individual in all possible worlds in which the individual exists and their reference does not depend on the descriptions we associate with that individual. Cf. Saul Kripke, Naming and Necessity (Cambridge MA: Harvard University Press, 1980), chap. 1. As it will be clarified later, I do no subscribe to a Kripke's style version of semantic externalism in this article. The notion of rigid designator will be used to illustrate a defective form of linguist communication that may take place in legal decision-making.
} 
opinion or testimony even though such an authority is not able to grasp the content of the law it applies.

It is worth pointing out that in the Psidax case the term ' $\mathrm{XYZ}$ ' has a content known to the experts appointed by the judge, but it is not the experts who fix the reference of this term from the legal point of view. The reference of 'XYZ' is authoritatively fixed by the judge who thereby legally qualifies the facts of the case. At the same time, the judge uses the term ' $\mathrm{XYZ}$ ' to determine whether the case at hand is governed by the law, but the content of ' $\mathrm{XYZ}$ ' is unintelligible to the judge, who defers to the experts in order to fix its reference. The opacity of law is therefore a bilateral phenomenon. When it manifests itself, it affects primarily the legal decision-maker, who does not fully understand the legal texts she uses to decide the case, with potentially pernicious effects, as we will see. However, the opacity of the law also affects the experts, who might be not able to evaluate the consequences that their opinion will bring about in the decisionmaking process.

Now, one could object here that the example just proposed describes a situation which is not actually found in legal practice. Although experts' opinions or testimony are often decisive in legal adjudication, no judge decides a case in the way previously outlined. In the U.S. legal system, for instance, judges do not usually appoint independent experts but simply act as 'evidentiary gatekeepers' with regard to testimony of the experts appointed by the parties. ${ }^{8}$ Even in those legal systems where the judge acts as fact finder and commonly appoints independent experts, the experts simply make available to the judge the relevant knowledge and all the facts that they consider relevant and reliable. Then the judge reaches her own conclusion on the basis of the total available evidence, and of what the law provides.

However, the Psidax case is not intended to faithfully represent a real situation but to highlight some aspects of reality on which we usually do not pay enough attention. As a matter of fact, opacity is a

\footnotetext{
${ }^{8}$ In the U.S. legal system, the judge is simply called upon to make a preliminary assessment of whether the scientific evidence adduced by the experts and their methodology are reliable, without interfering with the jury's role as trier of facts. Cf. Daubert v. Merrell Dow Pharms. Inc., 509 U.S. 579 (1993); General Elec. Co. v. Joiner, 522 U.S. 136 (1997); Kumho Tire Co. v. Carmichael, 526 U.S. 137 (1999). Notice that the example just proposed could be extended, with some additions, to the jurors of a trial jury, to administrative authorities, and to other legal authorities. For the sake of simplicity, I will mainly focus on the decision-making activity of the judge.
} 
phenomenon that frequently affects legal adjudication, judicial review and other forms of legal decision-making, even though we are not aware of it. Two examples drawn from case law may assist in clarifying the way in which the opacity of law manifests itself.

\section{A. Stalcup v. Peabody}

Donald D. Stalcup worked as a miner at the Peabody Coal Company for a period of about 30 years. In 1997 he was diagnosed with a severe form of pneumoconiosis, a chronic lung disease caused by exposure to coal dust. Donald Stalcup therefore filed for benefits under Article 922(a)(1) of the Black Lunge Benefit Act, which stated that in case of total disability of the miner caused by pneumoconiosis, the miner must be compensated during the disability period'. The administrative judge initially recognized Stalcup's right to compensation, but on appeal the Benefit Review Board (BRB) annulled the decision as the judge had 'misjudged the relevant evidence'. ${ }^{9}$ The BRB ordered the judge to carefully consider whether Donald Stalcup had actually contracted pneumoconiosis or whether his disability was attributable to other diseases. For this purpose the judge sought the advice of a committee of experts called to evaluate the clinical situation of the patient. Three of the five members of the commission stated that Donald Stalcup was not affected by pneumoconiosis, while the remaining members formulated an opposing diagnosis on the basis of a different etiology of the symptoms manifested by the patient, in conflict with the diagnosis reached by the other experts and equally founded on scientific literature. By virtue of the majority formed within the panel of experts, the judge denied compensation to Stalcup because he had not proven to have contracted pneumoconiosis.

If we consider the reasoning made by the judge in Stalcup, what was the contribution of the experts to the solution the case? The notion of opacity of law can be useful to answer this question. The term 'pneumoconiosis' was opaque to the judge since he did not competently know the scientific content of this term nor was able to fix its reference. Therefore, the judge resorted to the experts' opinion not only to ascertain if Stalcup actually contracted pneumoconiosis

\footnotetext{
${ }^{9}$ Stalcup v. Peabody Coal Co., 477 F.3d 482 (7th Cir. 2007).
} 
but also, and foremost, to determine what 'pneumoconiosis' means, i.e., the conditions of application of Article 922(a)(1). 'Pneumoconiosis' is in fact a technical term belonging to the language of pathological medicine. It is a term used by the legislature in the formulation of the law but whose scientific content was unintelligible to the judge. In addition, the experts' commission formulated two conflicting opinions on the conditions of application of the term 'pneumoconiosis', motivated by the fact that the scientific community was divided with regard to the scientific explanation of this pathology. Since the judge did not have technical skills in the matter, her decision was blindly based on the mere counting of votes. Just as in the Psidax example, the judge merely took the opinion of the majority of the experts to determine the full linguistic content of a statute, without being able to grasp the scientific reasons that justified his decision. In doing so, the judge failed to understand Article 922(a)(1) of the Black Lung Act, delegating, de facto, the exercise of judicial power to a panel of experts. Furthermore, the experts' opinion determined the full linguistic content of the legal text not on the basis of shared and consolidated scientific knowledge but on a majority vote. Thus, the criteria for choosing the experts, and their representativeness with respect to alternative explanations of the disease accredited in scientific literature, became crucial in the decision-making process. Not only did the experts 'replace' the judge in the understanding of the law, but their final opinion also remained controversial from an epistemic point of view.

\section{B. Upjohn v. The Licensing Authority}

According to Article 11 of the Directive 65/65 of the European Union, the competent authorities of the EU Member States are required to suspend or revoke the authorization to trade a medicinal product 'when it appears that the medicinal product is harmful under normal conditions of use'. In July 1991, the Medicine Control Agency (MCA) of the United Kingdom learned from a newspaper that a woman had murdered her mother under the effect of Trizolam, a medicine used for the treatment of insomnia produced by Upjohn Ltd. Based on the technical advice issued by the Committee for the Safety of Medicine, the MCA decided to suspend the marketing 
authorization for Trizolam as this medicine was harmful to health. The suspension was renewed until 9 June 1993, when authorization for the product was permanently revoked, despite the fact that the European Committee for Proprietary Medicinal Products and other ad hoc technical commissions had argued that the health benefits of Trizolam outweighed the risks arising from its use. The manufacturing company turned to the UK High Court of Justice calling for the annulment of the MCA's decision. Faced with the need to establish its jurisdiction on the matter, the High Court addressed a preliminary ruling to the Court of Justice of the European Union asking for clarification on the interpretation of Directive 65/65 and the way in which the courts of the Member States had to behave in cases such as these. In answering these questions, the European Court of Justice affirmed, among other things, that allowing competent national courts 'to replace their assessment of the facts' to that of the competent national judges is not an adequate way to guarantee the rights protected by the community law. ${ }^{10}$ The court added that 'a Community authority, in the exercise of its powers, when called to carry out complex assessments, has for this reason wide discretionary power [...], which does not imply that the Community judicature substitutes its evaluation of the de facto elements to that of the said authority. Thus, in such cases, the Community judicature limits itself to examining the substantive accuracy of the facts and the legal qualifications which this authority has derived from it'. ${ }^{11}$ On the basis of these considerations, the court concluded that EU law does not require Member States to establish a standard for judicial review of decisions concerning licenses for the trade in medical products.

Regardless of the conclusion reached by the court, it is interesting to focus on the reasons given by the judges to justify their ruling. The court considered the marketing conditions of Trizolam, established under Article 11 of Directive 65/65, purely as an evidential issue, not as an issue which required an interpretation of the Directive by the judge before whom the decision of the adminis-

\footnotetext{
${ }^{10}$ Case C-120/97 Upjohn Ltd. v. The Licensing Authority and Others (1999) 1 WLR 927, I-251, 333.

${ }^{11}$ Ibid. $\S 34$. More recently, the Court has specified that the judicial review of the measures requiring complex technical evaluations "is limited, from the point of view of merit, to the verification of the material accuracy of the facts, the absence of a manifest error of assessment of these facts and the accuracy of the legal consequences deriving from them”. Case T-168/01 Glaxo-Smith-Kline Services Unlimited v. Commission (2006) ECR II 2969, § 241
} 
trative authority had been challenged. That Trizolam was harmful constituted a mere factual question, ascertainable on the basis of the technical opinion of the competent administrative authorities, to which neither national judges nor EU judicature may, under any circumstances, substitute themselves.

However, what we have previously observed suggests a different reconstruction. The conditions under which a medicinal product is deemed harmful first depend on the content we attribute to the term 'harmful'. However, in compliance with the preliminary ruling of the European Court of Justice, the United Kingdom High Court decided to attribute to 'harmful' not the content that this term has in ordinary language, which the judges were able to master, but a technical content, established by MCA experts on the basis of scientific knowledge that the court neither possess nor was authorized to evaluate. In this sense, the Article 11 of Directive 65/65 became opaque for the national court as a result of the preliminary ruling of the European Court of Justice. The full content of this regulation was made to depend on expert knowledge subtracted from the consideration and evaluation of the national judge. In fact, from a logical point of view, in Upjohn the experts from the MCA first determined the conditions of application of the term 'harmful' (and so the full linguistic content of Article 11) and then ascertained, on the basis of the available evidence, whether these conditions were met by Trizolam.

If this reconstruction hits the mark, then the assumption of the European Court of Justice, according to which the authorization to trade a medicinal product is merely an evidentiary issue, is erroneous. The conditions under which a medical product can be put on the market are established by Article 11 of Directive 65/65, the content of which was 'opacified' by the European Court of Justice. The Court implicitly attributed the power to determine the full linguistic content of the Directive to an administrative agency, a content that could not be fully understood nor evaluated by the national judges. As a result, the decision of the national judge was taken blindly, thus running the risk of jeopardizing the legal protection of the rights involved. 


\section{WHY SHOULD THE OPACITY OF LAW BE A PROBLEM?}

The analysis of the examples which has just been offered may stir up some perplexities in the mind of the reader.

Firstly, it could be argued that experts' opinion and testimony have nothing to do with the determination of the content of legal texts. The problems considered up to now concern fact-finding and therefore evidentiary reasoning. In Upjohn the court simply found itself having to determine whether Trizolam was a harmful medicine, i.e., whether the sentence 'Trizolam is harmful' was true or false. Likewise, in Stalcup the court was asked to ascertain whether Donald Stalcup had contracted pneumoconiosis, i.e. the truth-value of the sentence 'Donald Stalcup suffers from pneumoconiosis'. In both cases, the experts did not contribute to identify the linguistic content of a legal provision but rather to ascertain a fact on the basis of the available evidence. On closer inspection, however, the experts played a much more pervasive role. In Stalcup and Upjohn the opinion of the experts was used both to determine the truth-value of factual statements and to determine the content of a linguistic expression ('pneumoconiosis', 'harmful') on which the full content of the relevant statute depended. Therefore, the experts unwittingly carried out an interpretative work closely related to fact finding, and logically prior to it.

Secondly, one could argue that the judge decided the Psidax case according to the literal meaning of the statute. If by simplicity we assume that the literal meaning of a linguistic expression is determined by the syntactic and semantic conventions that govern the use of this expression in a given context, then experts limit themselves to applying the linguistic conventions of their sectoral language. ${ }^{12}$ However, if we consider the Psidax example carefully, it is easy to see that the judge does not attribute, from a cognitive point of view, any content to the statute she applies. The judge simply fixes the reference of the statute on the basis of the experts' testimony, even

\footnotetext{
${ }^{12}$ It could be argued here that literal or conventional meaning by itself is not sufficient to determine the content of legal texts. Literal meaning is actually a vehicle for getting to a pragmatically enriched content that depends on a set of contextual information. See Andrei Marmor, Interpretation and Legal Theory. Second Edition (Oxford and Portland: Hart, 2005), chap. 2; Scott Soames, "Interpreting Legal Texts: What Is, and What Is Not, Special About the Law”, in S. Soames, Philosophical Essays, Volume 1: Natural Language: What It Means and How We Use It (Princeton: Princeton University Press, 2008), pp. 403-424. When a legal text becomes opaque, however, any contextual enrichment and modulation is blocked since the judge is not able to grasp the semantic content that the experts attribute to the text.
} 
though such an opinion is not intelligible. Therefore opacity should not be confused with literal meaning or literal interpretation. The content of a legal text cannot be considered to correspond to its literal or plain meaning if this content is not grasped by those who use it to decide a legal dispute. Literal meaning and literal interpretation in the law require not only that the judge applies an appropriate set of semantic (and pragmatic) rules but also that she be able to master these rules; a requirement that remains frustrated when a legal text is opaque.

Thirdly, it could be argued that opacity is in fact a problem of indeterminacy of legal language. ${ }^{13}$ Both Stalcup and Upjohn can be seen as borderline cases, in which it was not clear whether the law applied, and the opinion of the experts was used by the court to reduce the indeterminacy of statutory content in order to reach a decision. If we assume, for the sake of simplicity, that the indeterminacy of legal language depends on the communicative context in which legal texts are used, ${ }^{14}$ one could argue that in Stalcup and Upjohn the court lacked sufficient contextual information which was actually provided by the experts' testimony. ${ }^{15}$ If this is the case, opacity would not be an independent communicative problem but rather a form of contextual indeterminacy. We can reply to this by stating that the extension of an opaque term - the set of objects, events, states of affairs to which it applies - is usually determinate. In most cases, the content of an opaque legal text is sufficiently precise to exclude borderline cases. Furthermore, this content is neither determinate nor indeterminate for the judge, since the judge only partially understands it. ${ }^{16}$ It thus follows that opacity can not be reduced to linguistic indeterminacy, even though an opaque legal

\footnotetext{
${ }^{13}$ For a general overview on the indeterminacy of legal language, and related issues, see Brian Bix, Law, Language and Legal Determinacy (Oxford: Oxford University Press, 1993); Frederick Schauer, "A Critical Guide to Vehicles in the Park", New York University Law Review 83 (2008): pp. 1109-1134.

${ }^{14}$ See Marmor, Interpretation and Legal Theory, p. 133. Cf. also Scott Soames, "Vagueness and the Law", in A. Marmor (ed), The Routledge Companion to Philosophy of Law (New York: Routledge, 2012), pp. 95-108.

${ }^{15}$ Regarding the investigation of complex facts, whose explanation involves technical and scientific knowledge, Ron Allen maintains that the judge is not affected by cognitive deficits but by informational deficits, to the point that even the most difficult cases could be decided by anyone, once the necessary information has been acquired. See Ronald J. Allen, "Expertise and the Daubert Decision", The Journal of Criminal Law and Criminology 84 (1994): pp. 1157-75.

${ }^{16}$ More precisely, an opaque expression, such as any deferential representation, is not linguistically but epistemically indeterminate. See on this François Recanati, "Can We Believe What We Do Not Understand?", Mind \& Language 12 (1997): p. 87.
} 
text may prove semantically or pragmatically indeterminate when its content becomes transparent to the judge. ${ }^{17}$ Similarly to linguistic indeterminacy, however, opacity is a matter of degree. A linguistic term or expression can be more or less opaque depending on the degree to which one masters its content in a given linguistic domain. As we will see below, opacity becomes a problem when the judge is not able to discern the impact of an opaque legal provision on the content of the law.

Lastly, it might be argued that all regulations that include scientific or technical terms are to some extent opaque. The opacity of law would simply be the result of the choice made by the legislature to incorporate into the law expressions borrowed from scientific or technical languages - a choice that is obviously justified by the increasing complexity of the cases to be regulated. So, the reconstruction of the problem considered so far would be misleading. Also this objection, however, fails to hit the mark. Opacity is a problem that does not afflict legal texts as such but rather the linguistic communication that takes place in legal contexts. The idea that any legal text formulated in a non-legal, technical language is (to some extent) opaque implies that linguistic contents are independent both of the use we make of language in a communicative context and of the cognitive contribution of the speakers to the communicative process. But that is not the way things are. Opacity actually depends on the linguistic interaction between legal decision-makers on the one hand, and experts on the other. It is the epistemic asymmetry between these subjects that opacifies the law, not the fact that a legal text includes scientific or technical terms. If the judge, for instance, was able to fully understand the scientific or technical language in which the law is formulated, the law would not become opaque.

The discussion of these objections makes it possible to clarify under what profile opacity should be regarded as a problem. The answer to this question depends on the contribution that legal texts make to the content of the law or, in other words, on the difference

\footnotetext{
${ }^{17}$ One might object to this that opacity is actually a matter of vagueness. According to the epistemic theory of vagueness, the content of vague terms is perfectly determinate but unknowable, since we lack cognitive resources to fix its content in borderline cases. Cf. Timothy Williamson, Vagueness (LondonNew York: Routledge, 1994). It should be noted, however, that opaque expressions are not epistemically vague in the sense proposed by Williamson. Their content is not knowable by the judge but is perfectly accessible to the experts, who indeed provide the judge with sufficient information to fix the reference of the law to be applied.
} 
that legal texts make to legal obligations, permissions, rights, privileges etc. In the current jurisprudential debate, there are two main competing standpoints on the subject, that are based on different philosophical explanations of legal content.

According to the first one, which reflects the 'standard positivistic picture' of law, ${ }^{18}$ the contribution of legal texts to the content of the law is constituted by their linguistic content, i.e. by the normative information conveyed by the words and sentences that legal texts are composed of. Even though the standard positivistic picture is not committed to a specific conception of linguistic content, it is usually assumed that such content has a semantic and pragmatic dimension. Roughly, it depends on both the information encoded in the words and syntax of a language, and on the ways in which information is communicated in a given context. ${ }^{19}$ When a legal text becomes opaque, the information conveyed by it is not fully intelligible to the judge and as we will see, in same cases, even to the legislature. As a consequence, the communicative function of legal texts becomes defective. Opacity impedes the full understanding of semantic content, which is actually fixed by the experts, as well as any pragmatic enrichment and modulation of content in the context of adjudication. $^{20}$ If this is the case, the legal effect of opaque legal texts, and thus their contribution to the content of the law, is removed from the control of the corresponding legal authorities - both the lawmaker and those who are entrusted to apply the law -, and should be seen as illegitimate. ${ }^{21}$ A similar line of thought applies to those versions of legal positivism that cannot be easily reduced to the 'standard picture', such as Herbert Hart's.

\footnotetext{
${ }^{18}$ I borrow this expression from Mitchell N. Berman, "On Law and Other Normative Legal Systems", in D. Plunkett, S. Shapiro and K. Toh (eds), Dimensions of Normativity: New Essays on Metaethics and Jurisprudence (Oxford: Oxford University Press, 2019), p. 138.

${ }^{19}$ Cf., e.g., Andrei Marmor, The Language of Law (Oxford: Oxford University Press, 2014), chap. 1; Robyn Carston, "Legal Texts and Canons of Construction: A View from Current Pragmatic Theory", in M. Freeman and F. Smith (eds), Current Legal Issues: Law and Language (Oxford: Oxford University Press, 2013), p. 9.

20 The pragmatic enrichment and modulation of semantic content depends on textual and extratextual factors. For instance, the judge in the Psidax case cannot ascertain whether a legal text has more than one possible meaning or admits borderline cases; extend by analogy the application of a legal norm to similar cases; determine whether the law to be applied conflicts with other laws or principles; make it the case that linguistic content conveys the legislature's intention; foresee the social and political consequences of her ruling, etc.

${ }^{21}$ The relationship between opacity and political legitimacy will be elaborated in sec. v.
} 
In Hart's jurisprudential picture, legal rules such as statutes, regulations and constitutions do not simply convey authoritative linguistic contents. The concept of legal rule explains a complex social practice in which certain kinds of conduct are made obligatory by a set of social facts that are identified by the convergent practices of legal officials, and the officials' acceptance of legal rules as standards of conduct. Therefore, legal rules are first and foremost reasons for action that explain how it is the case that human conduct is governed by the law, ${ }^{22}$ and the content of law is determined, at its fundamental level, by a social practice among legal officials governed by Hart's rule of recognition. On that account, whatever legal rule provides guidance to human conduct only in so far as its content can be represented in thought, and endorsed in attitude, by those who participate in the legal practice. But, in the case of opacity, legal officials are not able understand the content of legal rules, nor can they envisage which legal obligation such a content purports to generate, even though legal officials may in fact accept opaque rules from the internal point of view. In the case of opacity, a cognitive element essential to legal decision-making is missing, and opaque rules cannot be considered as a by-product of the social practice at the foundation of law. ${ }^{23}$ Their content ultimately depends on the epistemic social practice of experts, although no power-conferring rule enables experts to modify legal obligations.

According to a different standpoint, typically maintained by the opponents of legal positivism, the linguistic content of legal texts contributes to the content of the law on the basis of more fundamental non linguistic normative facts such as moral principles or values. In Dworkin's view, for instance, the linguistic content of a legal text contributes to the content of the law only if it is consistent

\footnotetext{
${ }^{22}$ Herbert H.L. Hart, The Concept of Law. Third Edition (Clarendon Press: Oxford, 2012), pp. 10-11 and 94 ff. See on this Scott Shapiro, "On Hart's Way Out", Legal Theory 4 (1998): pp. 469-507; Kevin Toh, "Hart's Expressivism and His Benthamite Project”, Legal Theory 11 (2005): pp. 75-123.

${ }^{23}$ Similar considerations can be extended to Shapiro's planning theory of law. In Shapiro's view, legal norms are not reasons for action but rather plans through which legal institutions coordinate social behaviour and resolve doubts and disagreements about the moral matters that affect social life. See Scott Shapiro, Legality (Cambridge MA: Harvard University Press, 2011). Since the point of legal planning is to achieve some social ends, experts' testimony may compensate for the judge's lack of competence with regard to technical matters: experts help the judge to deliberate about the best means to achieve a certain end according to the "economy of trust" that characterizes a given legal system. Cf. ibid., p. 332 ff. In the case of opacity, however, the judge cannot discern whether the interpreted plan fits well with the other plans of the legal system, and allocates decision-making authority on experts even though this is at odds with the master plan. Therefore, the opacity of law may generate forms of irrationality in legal planning.
} 
with the set of legal principles that best fit and justify the institutional practice of the legal system, i.e. the past actions of legislatures, courts and other institutions. ${ }^{24}$ Mark Greenberg maintains, conversely, that the impact of the linguistic content of legal texts on the content of the law depends on all relevant values that make up the 'moral profile' of a legal system. Therefore, linguistic content generates a genuine legal obligation only if a moral obligation is obtained in virtue of the action of legal institutions. Now, when legal texts become opaque it is not possible to determine whether statutory linguistic contents are consistent with Dworkinian legal principles, nor will the practice of enacting and applying opaque laws find justification in these principles, at least in most current legal systems. At the same time, as Greenberg probably would say, opaque linguistic contents cannot generate genuine (moral) obligations. It is so because the judge is not in the position to accurately ascertain the impact of opaque linguistic content based on the more fundamental moral facts, i.e. the all-things-considered consequences of the application of this content on the moral profile of the legal system. ${ }^{25}$ In this sense, the 'opacification' of the law is at odds with the distinctive way in which legal institutions are supposed to create obligations, ${ }^{26}$ and opaque laws should be considered as defective objects in the legal system.

Before considering the different kinds of opacity that may affect the law, and the specific problems they give rise to, in the next section I will examine some important aspects of this phenomenon from the point of view of philosophy of language.

\section{INFERENTIAL COMPETENCE AND REFERENTIAL COMPETENCE}

The term 'opacity' is well known to philosophers of language and philosophers of logic, who usually trace it back to the notion of

\footnotetext{
${ }^{24}$ Ronald Dworkin, Law's Empire (Cambridge MA: Harvard University Press, 1984), pp. 284-286, 387-388.

${ }^{25}$ Mark Greenberg, "What Makes a Method of Legal Interpretation Correct? Legal Standards vs. Fundamental Determinants”, Harvard Law Review 130 (2017): p. 110.

${ }^{26}$ Cf. Mark Greenberg, "The Moral Impact Theory of Law", Yale Law Journal 123 (2014): p. $1321 \mathrm{ff}$. The same line of though can be extended to natural law theories such as Mark Marphy's. In Marphy's view, law is defective to the extent that it is not backed by decisive reasons for compliance. Mark C. Marphy, Natural Law in Jurisprudence and Politics (Cambridge: Cambridge University Press, 2006), p. 1. Therefore, if the content of a legal text is not fully intelligible, it is not possible to establish whether such content acquires reason-giving force in virtue of the common good of the political community. So, opaque norms do not provide sufficient reasons either to take or not to take a certain action.
} 
opaque context elaborated by Quine. ${ }^{27}$ Typically, a communicative context is opaque if, given a sentence $S$, it is not possible to substitute a sub-sentential component of $S$ with a component with the same reference while preserving the truth-value of $S$ in that context. Consequently, 'certain rules of inference, which in various contexts are valid, lead to formulate invalid arguments. ${ }^{28}$ Consider the following example:

(1) 'Cicero' contains six letters

(2) 'Cicero' and 'Tully' refer to the same person

Although (1) and (2) are true, the sentence

(3) 'Tully' contains six letters

is false, in spite of the principle of substitutivity salva veritate. The same can happen when a sentence is used to express propositional attitudes such as 'believing that...', 'knowing that...'. Consider the following example:

(4) Mary believes that the city of Tegucigalpa is in Nicaragua.

Now, although the expressions 'city of Tegucigalpa' and 'capital of Honduras' are co-referential, it would be erroneous to infer from (4) the following sentence:

(5) Mary believes that the capital of Honduras is in Nicaragua.

This is because Mary may not know that Tegucigalpa is the capital of Honduras, and because to believe that the capital of a state is in the territory of a different state is at odds with the status of being a capital. Quine used these examples to show that the semantic content of a linguistic expression is not reducible to what that expression stands for. There are uses of words in which the reference is sufficient to fix the semantic value of a sentence. But in the intensional contexts that we have just examined, this does not seem possible.

\footnotetext{
${ }^{27}$ Willard Van Orman Quine, From a Logical Point of View (Cambridge MA: Harvard University Press, 1953), p. $141 \mathrm{ff}$.

${ }^{28}$ Michael Lumsden, Existential Sentences: Their Structure and Meaning (London: Routledge, 2015), p. 82. See also Fabrizio Mondadori, "Referential Opacity", in P. Leonardi and M. Santanbrogio (eds), On Quine. New Essays (Cambridge: Cambridge University Press, 1995), pp. 230-247.
} 
Quine's analysis of opaque contexts helped, in the 1950s, to revitalize the Fregean distinction between sense (Sinn) and reference (Bedeutung) within the philosophical debate. While the reference is what a linguistic expression designates or stands for, the sense is the way in which the reference is given, that is, the way in which the designate can be thought. ${ }^{29}$ In other words, Fregean senses are conceptual entities that connect, form a cognitive point of view, a linguistic construct to its referent: they consist of what the speaker knows as a result of the fact that she masters a language. As is well known, Frege maintains that sense determines reference. In the Fregean perspective the predicate 'XYZ' applies to the Psidax if, and only if, the Psidax satisfies the set of properties that we conceptually associate with XYZ.

In the 1970's, however, Saul Kripke and Hilary Putnam proposed a series of influential arguments aimed at showing that no cognitive content satisfies the conditions of application of a linguistic expression in the case of proper names and natural kind terms. We can in fact be able to identify Albert Einstein, and therefore competent to fix the reference of 'Albert Einstein', even if we do not know that we are referring to the man who formulated the theory of special relativity in $1905 .^{30}$ In parallel, regardless of the properties that we commonly attribute to water and the way we use the term 'water', the extension of this term is fixed by the nature of water, i.e. by the causal-explanatory features of a sample of it, even if we do not know that water has the molecular structure $\mathrm{H}_{2} \mathrm{O} .{ }^{31}$ There are situations in which the content of a term or expression does not determine its reference, but rather the opposite. In this way semantic externalism

\footnotetext{
${ }^{29}$ Gottlob Frege, “Über Sinn und Bedeutung”, Zeitschrift für Philosophie und philosophische Kritik 100 (1882): pp. 25-50.

${ }^{30}$ Cf. Keith Donnellan, "Proper Names and Identifying Descriptions", Synthese 21 (1970): pp. 335358; Kripke, Naming and Necessity, chap. 3.

${ }^{31}$ Hilary Putnam, "Meaning and Reference", The Journal of Philosophy 70 (1973): pp. 699-711. Through the famous Twin Earth example, Putnam claimed that natural kind terms have an indexical component. The term 'water' refers to the substance that has a relationship of similarity with what we have stipulated to call water and which serves as a paradigm in our evaluations. See Hilary Putnam, "The Meaning of 'Meaning"”, in H. Putnam, Mind, Language and Reality (Cambridge: Cambridge University Press, 1979), p. 234. For a critique of Putnam’s semantic externalism see, e.g., Paul Boghossian, "What the Externalist Can Know A Priori", Proceedings of the Aristotelian Society 97 (1997): pp. 161-175; Peter Unger, Philosophical Relativity (Oxford: Oxford University Press, 2002), chap. 1.
} 
tries to account for the intuition that we may not know the conditions of application of a linguistic expression, or that we may identify these conditions incorrectly. This circumstance allows us to explain the way in which empirical research is conducted in natural science, as well as to justify the consideration of common sense according to which we frequently refer to things whose nature do not we fully understand. ${ }^{32}$ Semantic externalism also provides a revised explanation of deference to experts. In this perspective, the fact that we often defer to experts shows that what really matters, e.g., for the use of the term 'water' is the deep nature of water, that experts are supposed to know. ${ }^{33}$ According to the traditional view, on the contrary, we defer to experts because we acknowledge that they grasp the concept of water better than we do, so it is reasonable to submit to their authority when our reference-fixing use of 'water' is dubious or different from their own. Starting from the arguments of Kripke and Putnam, different philosophical strategies have been developed to defend the Fregean idea that reference depends, at least in part, on content, so as to hold together the cognitive aspects and the referential aspects that characterize the use of language, i.e., the fact that linguistic competence depends on what the speakers believe and know, and, at the same time, the fact that many things designated by linguistic expressions have features that are not captured by our concepts and linguistic practices.

In this sense, one could argue that the impact of experts' opinions and testimony on the content of legal texts depends on the metasemantic theory that is deemed correct, i.e., on what facts determine semantic competence, and how that competence ensures that a linguistic expression has a certain semantic content. ${ }^{34}$ According to Chalmers's rationalistic internalism, for instance, being competent in the use of a term is to be in an internal cognitive state that allows determining the extension of the term in all possible

${ }^{32}$ Cf. Tyler Burge, "Intellectual Norms and Foundations of Mind", Journal of Philosophy 83 (1986): pp. 697-720; Timothy Williamson, The Philosophy of Philosophy (Oxford: Clarendon Press, 2007): p. 125.

${ }^{33}$ This is the reason why Putman and Burge claim that words that are used deferentially by ordinary speakers should be given the meaning they have in the experts' idiolect. Putnam, "The Meaning of 'Meaning"”: p. 225 ff.; Tyler Burge, "Individualism and the Mental", Midwest Studies in Philosophy 6 (1979): pp. 73-121.

${ }^{34}$ This characterization of the task of a metasemantic theory has been proposed by Christopher Peacocke, A Study of Concepts (Cambridge MA: MIT Press, 1999): p. 17. For an overview of the wide range of metasemantic theories that are discussed in the current philosophical debate see Alexis Burgess and Brett Sherman (eds), Metasemantics. New Essays on the Foundation of Meaning (Oxford: Oxford University Press, 2014). 
worlds on the basis of apriori reflection alone. ${ }^{35}$ In this perspective, experts are idealized speakers that are able to identify the extension of a linguistic expression in all possible situations. However, rationalistic internalism provides no resources to explain the contextual dependence of actual, non-idealized experts' opinions, nor to address the problems of inter-contextual communication that are crucial to explain the opacity of law. Laura Schroeter's and François Schroeter's relational externalism, on the contrary, maintains that internal cognitive states combine with external factors to grant competence with a particular meaning. ${ }^{36}$ These links constitute the 'default unit' for semantic mapping, which may be defeated in certain situations and admits that the same expression can be governed by different competence conditions. In a similar vein, I assume in this article that semantic content is grounded on speakers' dispositions to use linguistic expressions, seen as a part of the speakers' psychological system. Hence, these dispositions may be afflicted by shortcomings and biases, as occurs in the case of opacity. Furthermore, speakers' dispositions depend on cognitive and perceptual connections with external factors that contribute to determine semantic content. These factors include the history of the speaker's linguistic interaction, the context of communication, the communicative standards adopted by the linguistic community, the metaphysical nature of the environment, etc. ${ }^{37}$

If one assumes this socio-cognitive version of externalism in metasemantics, the speakers' semantic competence can be conceived as composed of two interrelated aspects: inferential competence and referential competence. ${ }^{38}$ Inferential competence consists in the ability to manage the network of semantic relations among linguistic expressions in a given language. It is part of the inferential competence, for example, to know that if I walk then I move, that if Fred is

\footnotetext{
${ }^{35}$ David J. Chalmers, “On Sense and Intension”, Philosophical Perspectives 16 (2002): pp. 135-182. On the two-dimensional semantics that is at the basis of Chalmers's metasemantic project see David J. Chalmers, "The Foundations of Two-Dimensional Semantics", in M. García-Carpintero and J. Macia (eds), Two-Dimensional Semantics (Oxford: Oxford University Press, 2006), p. 55 ff.

${ }^{36}$ See Laura Schroeter and François Schroeter, "Normative Concepts: A Connectedness Model", Philosophers' Imprint 14 (2014): pp. 1-26.

${ }^{37}$ On socio-cognitive externalism in metasemantics see Diego Marconi, "Semantic Competence", in E. Fridland and C. Pavese (eds), The Routledge Handbook of Philosophy of Skill and Expertise (London: Routledge, 2020), pp. 409-418.

${ }^{38}$ Diego Marconi, Lexical Competence. Language, Speech, and Communication (Cambridge MA: MIT Press, 1997), p. 74.
} 
a kangaroo then Fred is an animal, or that if $\mathrm{X}$ is a contract then $\mathrm{X}$ is an agreement enforceable by the law. On the basis of this competence we are able to identify semantic relationships such as hyponymy, hyperonymy and synonymy, to provide the definition of a term, to formulate paraphrases, as well as to evaluate that the inference from 'Paris is west of Berlin' to 'Berlin is east of Paris' is sound, while the inference from 'George is married' to 'George is a bachelor' is unsound. The inferential competence of a speaker depends on, among other things, the knowledge of the rules that govern the use of language in a given speech community, that is, the set of inferential relations in which linguistic expressions are involved in the linguistic practices of that community. Referential competence instead consists of the ability to apply words to the world through the aid of our perceptual apparatus. Thanks to this competence, for example, I am able to say 'hat' when I see a hat and not when I see a rhino, or open the door and not the window when I intend to obey the command 'Open the door!'. 39

Now, although the inferential competence and the referential competence of the speakers are closely intertwined with each other already in the early stages of language learning, they nevertheless may be dissociated. Neuropsychology has shown that there are cases of brain-injured patients capable of accurately and competently defining many linguistic terms, and correctly identifying the inferences that characterize their use, without however being able to associate these terms with any object. ${ }^{40}$ Conversely, there are cases of patients who retain the ability to correctly designate objects by using words but not to articulate the inferential relationships that words have among themselves. ${ }^{41}$ This helps to highlight how the mastery of a language requires continuous cooperation between inferential competence and referential competence. When this

\footnotetext{
${ }^{39}$ Referential competence is composed of two aspects: the ability to trace objects starting from linguistic expressions ("language (mind) to world" ability) and the ability to use expressions in the presence of those objects ("world to language (mind)" ability). See Marconi, Lexical Competence, p. 77.

${ }^{40}$ Cf. Janice Kay and Andrew Ellis, "A Cognitive Neuropsychological Case Study of Anomia. Implications for Psychological Models of Word Retrieval”, Brain 110 (1987): pp. 613-629; Glyn W. Humphreys and M. Jane Riddoch, "Features, Objects, Action: The Cognitive Neuropsychology of Visual Object Processing, 1984-2004”, Cognitive Neuropsychology 23 (2006): pp. 165-183.

${ }^{41}$ Cf. Paola Marangolo, Fabrizio Piras and Wim Fias, “'I Can Write Seven but I Can't say It': A Case of Domain-specific Phonological Output Deficit for Numbers”, Neuropsychologia 43 (2005): pp. 11771188; David Kammerer, David Rudrauf, Ken Manzel and Daniel Tranel, "Behavioral Patterns and Lesion Sites Associated with Impaired Processing of Lexical and Conceptual Knowledge of Actions", Cortex 48 (2012): pp. 826-848.
} 
cooperation fails, comprehension and linguistic communication risk becoming defective.

The opacity of law is a communicative phenomenon that determines the dissociation between referential competence and inferential competence of legal decision-makers. In the Psidax example, for instance, the judge can fix the reference of 'XYZ' thanks to the experts' opinion, but she is not able to master the set of inferences which determine the inferential content of 'XYZ'. Consequently, the judge behaves like that person who, on discovering a lion in the living room, is able to say 'Lion!', while pointing his finger in the right direction, but knows neither that lions are ferocious animals and not appliances, nor that a lion in the living room could be very dangerous, so the person merely stays sitting quietly in his armchair. Similarly, the judge is in a position to fix the reference of ' $\mathrm{XYZ}$ ' is prohibited' on the basis of experts' opinion. But suppose that ' $\mathrm{XYZ}$ ' is actually an ambiguous term in the language of chemistry although this does not emerge from the opinion of the experts, who considered this information irrelevant and in any case beyond the judge's capacity for understanding. Imagine there are two variants of this substance: $\mathrm{XYZ}_{1}$ and $\mathrm{XYZ}_{2}$; the former being harmful to health, the latter not. Suppose now that the rationale of the legal provision in question is to protect human health. Based on a purposive interpretation of ' $\mathrm{XYZ}$ is prohibited', it will be justified to prohibit the marketing of Psidax only if Psidax is $X Y Z_{1}$, whereas this prohibition will not be justified if Psidax is $\mathrm{XYZ}_{2}$. However, the judge in the Psidax case is precluded from any interpretative reasoning of this kind, since she does not master, from an inferential point of view, the content of ' $\mathrm{XYZ}$ '.

Returning in conclusion to opaque contexts, we could say that a linguistic expression such as 'XYZ is prohibited' may become opaque - causing the user violate the principle of substitutability of coreferential terms - since the experts' opinion operates in judicial reasoning the same way a sentence that expresses a belief does in intensional contexts. Within the reasoning of the judge, the statement 'Psidax is XYZ' can in fact be reformulated as follows

(6) The judge believes that Psidax is XYZ 
Suppose now that 'XYZ' and the expression 'aromatic cycle compound consisting of four carbon atoms and one of sulfur bound in a ring structure $\left[\mathrm{XYZ}_{1}\right]$ or in an aliphatic linear structure $\left[\mathrm{XYZ}_{2}\right]^{\prime}$ refer to the same chemical compound. On the basis of the principle of intersubstitutivity of coreferential expressions, we could validly infer

(7) The judge believes that Psidax is a straight aromatic cycle compound consisting of four carbon atoms and one of sulfur bound in a ring structure or in an aliphatic linear structure

However (7) is clearly false, because the judge does not know the language of chemistry nor the inferential content of ' $\mathrm{XYZ}$ '. The judge believes that the propositional content expressed by 'Psidax is XYZ' is true, but she does not have a direct belief in that content. ${ }^{42}$

As noted by Quine, this makes the linguistic communication non transparent, since the judge is assumed to have a belief that she actually neither has nor could have. A belief that justifies a different solution of the case at hand.

\section{KINDS OF OPACITY IN THE LAW}

Once the linguistic aspects of opacity have been clarified, attention must be given to the different forms this phenomenon takes on in the law. I will propose two different classifications of opacity below: one related to the sources of this phenomenon, the other to the inferential competence that the understanding and the interpretation of legal texts requires. As regards the sources of opacity, there are mainly of two kinds: opacity may arise following a choice of the legislature (default opacity) or a choice of the judge (deliberate opacity). As for the inferential skills involved, I will distinguish between definitional opacity and ontological opacity. It should be no-

\footnotetext{
${ }^{42}$ On the distinction between direct and indirect beliefs in deferential speech-acts see Keith Donnellan, "There Is a Word for That Kind of Things: An Investigation of Two Thought Experiments", Philosophical Perspectives 7 (1993): p. 167. According to Recanati, we should say here that the judge "quasi-believes" that Psidax is XYZ, in the sense that the judge accepts the sentence 'Psidax is XYZ' and is prepared to assert it, even though she does not fully understand its content. Recanati, "Can We Believe What We Do Not Understand?": p. 84. Following Recanati, the problem considered in this section could be analysed by means of the deferential operator $\mathrm{R}_{\mathrm{X}}(\cdot)$, that makes explicit the tacit reference $\mathrm{R}$ of the speaker to the use of the expression in brackets made by the cognitive agent $\mathrm{x}$. In this perspective, the propositional attitude conveyed by the sentence 'the judge believes that Psidax is XYZ' is 'the judge believes $\mathrm{R}_{\text {expert }}$ (Psidax is XYZ)'. Cf. François Recanati, "Deferential Concepts: A Response to Woodfield", Mind \& Language 15 (2002): p. 458. However, this account is based on some demanding assumptions with regard to the nature of mental meta-representations that cannot be discussed here.
} 
ted that these classifications are proposed here in order to shed light on different aspects of the same phenomenon. They are therefore neither mutually exclusive nor jointly exhaustive. Furthermore, it bears emphasis that my aim in this section is to outline a broad picture of the different forms of opacity that take place in the law. So, I will simply provide a map of problems without going into all their details and implications.

\section{A. Default Opacity}

Legislatures often enact legal provisions that include technical terms and expressions borrowed from sectoral languages. Typically this occurs when the subject of regulation involves highly specialized knowledge and skills: think of the discipline of medical activity, economic and financial activities, construction, environmental protection, etc. Through the use of sector-specific technical languages, legislatures are able to identify the subject of regulation more precisely and to provide targeted protection tools. The specialization of statutory language is usually justified by the need to make law more efficient. As Adrian Vermeule pointed out, 'an optimal decisionmaking process requires an optimal collection of information'. ${ }^{43}$ As far as legislation is concerned, this translates into the need to formulate detailed and precise legal provisions on the basis of all the relevant knowledge available so as to minimize the transaction costs of legal regulation. To achieve this, individual legislators or legislative committees delegate experts in the field of regulation to draft the legal text that will then be approved by the legislative assembly. As a result, legislation may be opaque for the members of the legislative body too, who do not master the inferential content of the technical terms and expressions used by the drafters of statutory language. Even if one assumes that the experts delegated to draft a legal text act as faithful agents of the individual legislators, and use those technical terms and expressions that convey the individual legislators' intentions or purposes, what matters is that individual legislators are not able to fully understand the law that they make.

\footnotetext{
${ }^{43}$ Adrian Vermeule, "The Parliament of Experts", Duke Law Journal 58 (2009): p. 2244. It is not possible, in this article, to examine the wide rage of issues related to the "expertisation" of policy making. These issues encompass concerns over experts' accountability, independence, trustworthiness, epistemic reliability, cultural biases, etc. For an overview, see Catherine Holst and Anders Molander, "Epistemic Democracy and the Role of Experts", Contemporary Political Theory 18 (2019): pp. 541-561.
} 
When this occurs, legal texts are opaque by default for those who are called upon to use them in legal decision-making. It is apparent that default opacity generates a number of concerns.

The first is related to legislative authority. In democratic legal systems, individual legislators are granted the authority to produce legislation. And that authority is only effective when it gives the possessor the power to determine the content of legislation. ${ }^{44}$ But individual legislators cannot be said to have determined the content of legislation if they are not in the position to fully understand the legislative text enacted by the legislative body. Therefore, in the case of default opacity, the authority to enact legislation is separated from the power to determine the linguistic content of legislation: this power is actually exercised by the experts who drafted the text. In this sense, default opacity converts experts' epistemic authority into a de facto legislative authority, even though this normative status is not granted to experts by the law nor can it be considered legitimate in a democratic legal system. ${ }^{45}$

The second concern is related to the effects of default opacity on judicial decision-making. As noted above, the judge does not usually have the inferential resources and the epistemic abilities to master the opaque language adopted by the legislature and is therefore forced to use experts' opinion and testimony to determine both the full content of the relevant legal texts and the facts of the case. When this occurs, the judge is not able to ascertain the impact of opaque legislative pronouncements on the content of the law. Scientific or

\footnotetext{
${ }^{44}$ Cf. James A.E. Macpherson, "Legislative Intentionalism and Proxy Agency", Law and Philosophy 29 (2010): p. 19.

${ }^{45}$ It should be added that the epistemic authority of the experts who act as assistants to individual legislators can be disputed, given that para-legislative experts are appointed on the basis of a political choice. See Mark B. Brown, Science in Democracy. Expertise, Institutions, and Representation (Cambridge MA: MIT Press, 2009), chap. 4.
} 
technical expressions incorporated into the legislation operate as rigid designators in the reasoning of the judge, who will therefore decide the case blindly, regardless of any other relevant legal reason that may justify a different judicial outcome.

As a result of the situation just described, legislation and adjudication run the risk of being deprived of legitimate authority. ${ }^{46}$ The political choice of the legislature tend to be substituted with the choice made by experts or technical agencies outside the democraticconstitutional circuit, a choice that the members of the legislative assembly are not able to fully understand. At the same time, in the case of default opacity the judge is not in the position to determine the impact of linguistic legal contents on the obligations, permissions, rights and privileges of the law addressees. Hence, the decision of a legal dispute is not based on what the law provides, all-thingsconsidered, and cannot be regarded as legally justified. It is worth emphasizing that these considerations are not meant to undermine experts' contribution to the improvement of the epistemic quality of political and legal decision-making. This contribution is inescapable in many areas of legal regulation, and enhances the 'truth sensitivity' of both legislation and adjudication. ${ }^{47}$ The notion of default opacity simply highlights a defective form of communication between experts and institutional decision-makers, and the troublesome consequences it gives rise to.

\footnotetext{
${ }^{46} \mathrm{I}$ am using here the notion of legitimate authority in a loose sense: an authority is legitimate if it is politically and legally justified. The considerations proposed in this section are therefore compatible with different conceptions of legitimate authority. If we consider Raz's service conception, for instance, one could argue that an opaque legal directive does not meet the requirements of the Dependence Thesis and the Normal Justification Thesis. An opaque legal directive is not based on all the relevant independent reasons which already apply to the subjects of the directive, nor is it possible to determine whether following such a directive leads those subjects to better comply with those reasons. Cf. Josef Raz, The Morality of Freedom (Oxford: Oxford University Press, 1986), p. 38 ff. A similar problem arises if one embraces a procedural conception of legitimacy that links authority to democratic decision-making. Cf., e.g., Jeremy Waldron, Law and Disagreement (Oxford: Oxford University Press, 1999), pp. 84-85; Thomas Christiano, "The Authority of Democracy", The Journal of Political Philosophy 12 (2004): p. 142 ff. In the case of default opacity, the content of legislation cannot be reasonably considered as the aggregation of individual preferences, nor as the outcome of a process of public deliberation, since this content is not fully accessible to those who enact the legislative text.

${ }^{47}$ Cf. Thomas Christiano, "Rational Deliberation Among Experts and Citizens", in J. Parkinson and J. Mansbridge (eds), Deliberative Systems: Deliberative Democracy at the Large Scale (Cambridge: Cambridge University Press, 2012), p. 29. The idea that the delegation of powers to unelected bodies may meet, under some conditions, the requirements of democracy and the rule of law is defended, among others, by Frank Vibert, The Rise of the Unelected. Democracy and the New Separation of Powers (Cambridge: Cambridge University Press, 2007), and Frank Fischer, Democracy and Expertise. Reorienting Policy Inquiry (Oxford: Oxford University Press, 2009). This idea will be reconsidered in the last section of this article.
} 


\section{B. Deliberate Opacity}

A statute or regulation can become opaque even by the judge's initiative. This happens when the latter attributes a non-transparent linguistic content, provided by the experts, to terms or expressions of ordinary language that occur in the law. ${ }^{48}$ The legal text is made opaque here because the judge deliberately chooses to attribute to it a content that she does not master from an inferential point of view. This choice generates a form of context shifting. The contextual enrichment and modulation of linguistic content does not take place in a context that the judge masters in the first place, and is shifted to a target, specialized context that the judge does not know. Consequently, the content of a term or expression, and the truth value of the sentences in which this term or expression occurs, may significantly vary from one context to the other. ${ }^{49}$ To address this problem, the judge defers to experts who fix linguistic content in the target, specialized context, and provide the judge with sufficient information to identify the subject and the scope of the regulation, even though the judge does not have the inferential competence to master this content and cannot re-contextualize it within the legal domain.

The reasons why judges intentionally defer to experts when determining the linguistic content of legal texts are closely linked to the increasingly pervasive role played by experts' opinion and testimony in fact finding. As already mentioned in the opening, the specialization of knowledge in many fields of human activity makes the contribution of experts inevitable, precisely because the judge or the jurors are not able to determine the truth value of many factual statements to be evaluated in fact finding. However, the role granted to experts 'reflects back' on the content of the legal texts. To

\footnotetext{
${ }^{48}$ This is a typical case of semantic deference. Semantic deference takes place when: (1) ordinary non-expert speakers know that the word $W$ is susceptible to a different technical use from its ordinary use; (2) speakers believe that the way in which experts use $W$ is the correct one; (3) speakers are willing to modify their use of $W$ where this is inconsistent with that of the experts. François Recanati, Oration Obliqua, Oratio Recta. An Essay on Metarepresentation (Cambridge MA: MIT Press, 2000), p. 272 ff.; Diego Marconi, "Semantic Normativity, Deference and Reference", Dialectica 66 (2012): pp. 273-287.

49 On context shifting see, e.g., Charles Travis, "Meaning's Role in Truth", Mind 100 (1996): pp. 454455. It seems to me that deliberate opacity meets the requirements of the tests for genuine context shifting proposed by Herman Cappelen and Ernie Lepore, Insensitive Semantics: A Defense of Semantic Minimalism and Speech Act Pluralism (Oxford: Blackwell, 2005), chap. 7. As we have seen in sec. IV, given an opaque expression OE, OE passes both the Inter-Contextual Disquotation Test (there can be false utterances of 'OE' event though $\mathrm{OE}$ ) and the Inter-Contextual Disquotational Indirect Reports Test (the indirect report in context $\mathrm{C}$ of the utterance of 'OE' in context C', where $\mathrm{C}$ is different from $\mathrm{C}$ ', can make the indirect report false).
} 
determine whether the case is covered by the law, the judge is inclined to attribute a scientific-technical content to a number of terms or expressions that recur in legal texts - such as 'death', 'dangerous', 'dominant position', 'consumer welfare', etc. - instead of their ordinary meaning, so as to match the content attributed to the same expressions by the experts in fact finding. In other words, it is the contemporary evolution of evidentiary reasoning that requires treating some expressions of everyday use, whose inferential content usually depends on common knowledge, as rigid designators, whose content depends on scientific or technical knowledge. When this happens, the law is deliberately made opaque.

However, it could be argued that the fact that the law is sometimes made opaque by the judge is actually a guarantee for legal certainty, for the predictability of judicial decisions, and for the equality of citizens before the law. As a matter of fact, the opacity of law prevents judicial discretion and judicial law-making since the subject-matter and the scope of the regulation are epistemically determined on the basis of expert knowledge alone. But this is only apparently the case. Deliberate opacity, not unlike default opacity, risks bringing about unequal treatment and legal uncertainty. First, when the law becomes opaque courts determine the subject-matter and the scope of the law on the basis of epistemic reasons that are not intelligible to them, reasons that could be not consistent with the legal reasons relevant to the case at hand. Second, in many cases science is uncertain, either because we do not have enough knowledge to unequivocally determine the scientific or technical content of the expressions incorporated into legal texts, or because such contents are controversial within the scientific community. In the aforementioned case, the impact of an opaque regulation on the content of the law becomes unpredictable at the expense of legal certainty and fairness.

\section{Definitional Opacity}

In the previous two sections we have observed that opacity of legal language depends, in first instance, on a choice made by the legislature or by the judge. We will now examine the different kinds of inferential competence that can be involved in this phenomenon. 
Firstly, a law can be opaque from a definitional point of view. This happens when the content of the terms or expressions that perform a referential function in a legal text is fixed by a definition that is not accessible or intelligible by the judge. In many domains of discourse the content of linguistic expressions is specified by definitions that help eliminating ambiguities and to reduce vagueness. In specialized languages, definitions typically have an explicative function. ${ }^{50}$ They do not purport to capture all aspects of the use of a word or expression but, rather, the central uses of it for a certain purpose in a certain context. Therefore, it is the purpose for which a definition has been formulated in a given context that determines its condition of explicative adequacy. ${ }^{51}$ When a definition of this sort is deferentially used in a different context by those who do not master the specialized language in question, or are not aware of the purpose for which the definition was originally provided, the explicative definition changes its function and turns into a stipulative definition. It fixes the reference of the defined term or expression rigidly, independent of the explanation associated to it. ${ }^{52}$ Consequently, in the case of definitional opacity the inferential content of the expression remains unintelligible to those who apply it according to its stipulative definition.

This kind of opacity becomes problematic in the law in those cases in which the opaque definition does not satisfy the conditions of adequacy that characterize the legal system. To give an example of this, imagine that in a legal system statutory law requires bread producers to use only 'natural flavourings'. Imagine, moreover, that the regulation does not contain any rule defining the expression 'natural flavours' but that the National Association of Bakers (NAB) has established a definition of this expression within its own selfregulation code. Imagine that according to such a definition, a certain food substance, let us call it ABC, is not included among the natural flavours because its exclusion would guarantee the members of the NAB a dominant position on the market. Imagine now, if you will, that a dispute arises involving a bread maker using $A B C$, and

\footnotetext{
${ }^{50}$ On the idea of definition as explanation see Rudolf Carnap, Meaning and Necessity: A Study in Semantics and Modal Logic (Chicago: University of Chicago Press, 1956), pp. 8-12.

${ }^{51}$ Nuel Belnap, “On Rigorous Definitions”, Philosophical Studies 72 (1993): p. 129 ff.

${ }^{52}$ Kripke has shown that a stipulative definition can be used to fix the reference of a term rather than to give its meaning: Kripke, Naming and Necessity, pp. 54-55.
} 
that the judge decides the case on the basis of the statute referred to above. Let us assume that the judge decides to appoint a panel of experts to settle the dispute, who are called to determine whether the bread produced by the claimant contains only natural flavourings. Since the NAB is the most authoritative association in the sector, with knowledge and skills recognized in the field, the experts will adopt the definition of 'natural flavours' given by the NAB, according to which $\mathrm{ABC}$ it is not a natural aroma. Based on the experts' opinion, the judge will therefore ban the production of bread containing ABC. It is easy to note that this decision is disputable. If the judge prohibits the production of bread containing $\mathrm{ABC}$ on the basis of the definition of the NAB, the applied standard will conflict with antitrust law, i.e., with other laws and standards pertaining to the legal system, without the judge having the possibility of knowing this. The emergence of this conflict is due to a definition that the judge does not know or master, a definition that is used in the experts' opinion and that determines the extension of 'natural flavours' and thus the scope of the law.

\section{Ontological Opacity}

A legal texts becomes opaque from the ontological point of view if two conditions obtains. First, the content of the sub-sentential elements that determine the scope of the law, i.e. the set of cases to which the law applies, is fixed by the characteristics that expert knowledge attributes to the object of regulation. Second, these characteristics are not competently known by those who apply the law.

This is the most widespread kind of opacity in legal practice. It typically manifests itself when a legal text contains terms or expressions that escape the understanding of the legal decisionmakers. In this case, the characteristics or properties attributed to the object of regulation by specialized knowledge essentially contribute to fix the content of legal texts via experts' opinion. Ontological opacity can take two different forms, which we could call, respectively, moderate and radical opacity.

Moderate ontological opacity arises when the characteristics attributed by the experts to the object of regulation are not contro- 
versial within the relevant scientific community. This happens when a scientific community has elaborated common standards on the basis of which it is justified to assert that any object, event, or state of affairs belonging to $S$ has characteristics $p_{1}, p_{2}, p_{3} \ldots p_{n}$. Therefore, the truth value of a factual claim such as ' $x$ is $S$ ' can be determined by a court, a jury, or an administrative authority on the basis of these standards, thanks to the information provided by the experts. As already noted, however, when the class term ' $S$ ' is used as a rigid designator, and the legal decision-maker does not have the inferential competence to use ' $S$ ', the law becomes moderately opaque. The opacity of law is moderate in this case because the legal decisionmaker could in principle acquire the inferential competence sufficient to grasp the full content of the opaque legal text.

The fact that law is moderately opaque, in the sense just stated, does not make the problems that this phenomenon triggers less relevant. Consider the following example ${ }^{53}$ : imagine that a statute gives the right to a disability pension to people suffering from arthritis. It would be up to medical science to determine under what conditions a person suffers from arthritis, since 'arthritis' is a medical term referring to a state of affairs whose characteristics are studied by this science. Thanks to the knowledge provided by medical science, the judge is able to establish the reference of the term 'arthritis' and the truth value of a sentence such as 'John suffers from arthritis'. Let us now imagine, just for the sake of argument, that medical research finds that arthritis is actually a genetic disease affecting only a certain group of individuals on a racial basis. Let us also assume that this information is not included in the opinion provided by the experts, who have not been asked to specify the causes of this pathology. Therefore, granting a disability pension under this statute could create unequal treatment of individuals on the basis of their race, i.e., one could argue that the statute infringes upon the principle of non-discrimination. But the judge who makes use of the experts' opinion is not able to grasp this aspect, since the term 'arthritis' is opaque to her. Therefore, the judge is not in a position to identify the impact of her ruling on the legal obligations, permission, rights and privileges that make up the law. On the other hand,

\footnotetext{
53 A similar example can be found in Tyler Burge, "Individualism and the Mental", Midwest Studies in Philosophy 4 (1979): pp. 73-121.
} 
experts can help the judge only in so far as they know that the genetic origin of the disease can be legally relevant, i.e., if they are able to master the set of inferences in which the term 'arthritis' is involved in the relevant legal context. But if this does not occur, the term becomes opaque even in the eyes of the experts.

The problems raised by ontological opacity become even more serious when the distinctive characteristics of the subject of regulation are uncertain or controversial for expert knowledge. Consider the term 'pneumoconiosis' contained in the statute applied in Stalcup. The content of this term was opaque for the judge, who resorted to a pool of experts to fix the reference of the statute without being able to fully understand its content. A further problem that arises in cases such as Stalcup lies in the fact that the conditions of application of the term 'pneumoconiosis' are controversial within medical science itself: experts disagree on what this term actually means. In the case of disagreement among experts, it becomes puzzling to establish the epistemic contribution that should be recognized to experts' opinions in the formation of the indirect beliefs of the judge, and the weight to be given to these opinions in decision-making. ${ }^{54}$ Ontological opacity becomes radical in cases like these since it cannot be avoided by means of the acquisition of a specialized inferential competence by the legal decision-maker. When ontological opacity is radical, the judge must choose the best scientific explanation of the state of affairs that fixes the reference of an opaque term, although she does not have the epistemic competence to make this choice.

\section{CONCLUSIVE REMARKS}

As I have tried to show in these pages, opacity in the law raises questions of interest both for legal theory and legal practice.

The analysis of this phenomenon offers, above all, some food for thought for those who are interested in the study of legal language. Traditionally, legal theory has paid great attention to the indeterminacy of the content of legal texts and to the problems that this may generate. Phenomena such as generality, ambiguity, vagueness

\footnotetext{
${ }^{54}$ It is not possible to discuss these problems here. For an overview of the epistemology of disagreement see Jonathan Matheson, The Epistemic Significance of Disagreement (Basingstoke: Palgrave Macmillan, 2015); David Christensen and Jennifer Lackey (eds), The Epistemology of Disagreement: New Essays (New York: Oxford University Press, 2013).
} 
and defeasibility are still at the centre of countless theoretical debates which end by focusing attention on the characteristics of judicial discretion. Opacity presents us with a completely different problem. An opaque legal text is not indeterminate but, on the contrary, is semantically and pragmatically over-rich and precise for those who are called upon to use it in legal decision-making, to the point that the decision is taken blindly. The reopening of a space for legal reasoning constitutes the antidote to opacity and makes it possible to avoid the most pernicious consequence of this phenomenon: the fact that experts come to tacitly replace the legislature, the judge or other legal authorities in legal decision-making.

The study of opacity has reflections worthy of attention for the analysis of judicial reasoning too, with particular regard to the traditional distinction between questions about facts (quaestio facti) and questions about law (quaestio iuris). Reasoning on facts and reasoning on questions of law are usually described as distinct inferential processes. The first is oriented to ascertain the truth value of factual claims while the second is for the identification of the law that governs the case. Now, it is well known that these two kinds of reasoning are closely related to each other. The search for the relevant facts is conditioned by the law chosen to regulate them; on the other hand, the identification of the law of the case depends on the evidence brought to the attention of the court. When opacity occurs, however, this correlation is broken. In the case of opacity, experts' opinion or testimony about facts fixes the reference of the statute to be applied, i.e. the subject matter and the scope of the regulation. In this sense, evidentiary reasoning contributes to determining the content of legal texts, with all the problems that this may bring about.

At this point one might object that opacity of law cannot be actually eliminated in legal systems such as ours. The cognitive contribution of experts is indispensable and valuable, both in the drafting of legal standards and in court. Furthermore, the epistemic asymmetry between experts and legal decision-makers is constitutive, and its degree varies on the basis of the subject of regulation, the purpose of the law-maker, and the kind of expertise involved in fact finding and adjudication. Therefore, it is reasonable to believe that there are cases in which the legally proper thing to do (whatever 
it is that we take 'legally proper' to mean) is to defer to experts' opinion even when it bears on the determination of the content of relevant legal texts. ${ }^{55}$ If all that holds true, the question is: how much opacity should we accept in our legal systems? The answer to this normative question depends on the characteristics of a legal system and its foundational principles. ${ }^{56}$ In a legal system where democracy and fairness are considered principles of this sort, opacity should be kept firmly under control. In the event of default opacity, as we have seen, the legislative authority of the legislature risks being replaced by the alleged epistemic authority of the experts who draft legal texts, thus undermining the legitimacy of law-making. In the case of deliberate opacity, the judge's deference to experts may constitute a serious interference with the principle of equality and fairness for the judge is not able to determine the impact of a legal text on the content of the law. Therefore, in those legal systems where the principles of democracy and fairness are a constitutive part of what the law is, opacity should be reduced to such an extent that its practical consequences do not infringe upon such principles. What is the best way to achieve this result? This calls into question the longstanding debate about whether legal decision-makers are to be educated by or to defer to experts. ${ }^{57}$ According to some, expert's opinions in court should provide the necessary background information to enable the judge or the jurors to determine the facts of the case on the basis of their own reasoning. Others claim that the legal decision-makers should simply defer to expert opinions because experts are better situated to ascertain the facts of the case on the basis of scientific or technical knowledge. The considerations proposed so far show that neither of these two options should be welcome. The opacity of law can be kept under control if legal decision-makers and experts cross their inferential competence and continuously coop-

\footnotetext{
${ }^{55}$ I am grateful to an anonymous reviewer for pointing out this.

${ }^{56}$ In this article I do not take a position as to whether these principles constitute the linguistic content of normative texts (e.g. constitutions), the interpretative reconstruction of the practice of a legal system, or depend on more fundamental moral facts. From the perspective defended in this paper, the opacity of law is not necessarily correlated to a certain jurisprudential standpoint, even though various theories of the nature of law may conceive the implications and consequences of this phenomenon differently.

${ }^{57}$ See, e.g., Ronald J. Allen and Joseph S. Miller, "The Common Law Theory of Experts: Deference or Education?”, Northwestern University Law Review 87 (1993): pp. 1131-1147; Emily H. Meazell, "Super Deference, the Science Obsession, and Judicial Review as Translation of Agency Science”, Michigan Law Review 109 (2010): pp. 733-784.
} 
erate with each other. More precisely, opacity loses its problematic character in law if two conditions are met. First, legal decisionmakers should acquire a level of inferential competence in the use of the scientific or technical expressions incorporated into legal texts that is sufficient to identify the impact of these expressions on the content of the law. Second, experts should acquire the inferential competence in the use of legal language necessary to provide all the relevant information that is needed to fix the reference of scientific or technical expressions according to what the law provides, allthings-considered. ${ }^{58}$ As Putnam pointed out, the division of linguistic labour that characterizes various fields of human activity must be accompanied by a 'structured cooperation' between the speakers. ${ }^{59}$ If such cooperation fails, opacity becomes pervasive and pernicious. However, the way in which the cooperative interaction between experts and legal decision-makers should be structured in a legal system is still an open question that stimulates further philosophical investigation.

\section{FUNDING}

Open access funding provided by Università Commerciale Luigi Bocconi within the CRUI-CARE Agreement.

\section{OPEN ACCESS}

This article is licensed under a Creative Commons Attribution 4.0 International License, which permits use, sharing, adaptation, distribution and reproduction in any medium or format, as long as you give appropriate credit to the original author(s) and the source, provide a link to the Creative Commons licence, and indicate if changes were made. The images or other third party material in this article are included in the article's Creative Commons licence, unless indicated otherwise in a credit line to

\footnotetext{
${ }^{58}$ On the difference between scientific reasons and legal reasons, and their interface in legal practice, see Susan Haack, "Truth and Justice, Inquiry and Advocacy, Science and Law", Ratio Juris 17 (2004): p. 17; Joseph Sanders, "Science, Law, and the Expert Witness", Law and Contemporary Problems 72 (2009): pp. $63-90$.

${ }^{59}$ Putnam, "Meaning and Reference": p. 706.
} 
the material. If material is not included in the article's Creative Commons licence and your intended use is not permitted by statutory regulation or exceeds the permitted use, you will need to obtain permission directly from the copyright holder. To view a copy of this licence, visit http:// creativecommons.org/licenses/by/4.0/.

\section{Department of Legal Studies}

Bocconi University, via Röntgen 1, 20136, Milan, Italy

E-mail: damiano.canale@unibocconi.it

Publisher's Note Springer Nature remains neutral with regard to jurisdictional claims in published maps and institutional affiliations. 